\title{
GALLBLADDER PERFORATION- PRESENTING AS AN ACUTE ABDOMEN
}

\author{
Gajendiraraj ${ }^{1}$, A. Ramesh ${ }^{2}$, Balakrishnan $R^{3}$
}

${ }^{1}$ Associate Professor, Department of General Surgery, Government Vellore Medical College and Hospital, Vellore. ${ }^{2}$ Assistant Professor, Department of General Surgery, Government Vellore Medical College and Hospital, Vellore. 3 Junior Resident, Department of General Surgery, Government Vellore Medical College and Hospital, Vellore.

\section{ABSTRACT}

\section{BACKGROUND}

Gallbladder perforation is a rare but life-threatening complication of acute cholecystitis. About $2 \%$ to $15 \%$ of patients with acute cholecystitis may be complicated with perforation of gallbladder. It may present as an acute abdomen which is a rare presentation which requires an emergency intervention.

The aim of the study is to emphasise the importance of gallbladder perforation as one among the differential diagnoses of cases presenting as acute abdomen.

\section{MATERIALS AND METHODS}

About 212 cases presented as acute abdomen were reviewed from a period between 2013 to 2016. And among these study participants, the number of intraoperative diagnosis as gallbladder perforation was collected. These gallbladder perforation cases were estimated with regard to the age, gender, type of perforation and associated comorbidities.

\section{RESULTS}

20 cases were found to have gallbladder perforation. All these cases were presented as an acute abdomen. It was more seen in elder age group with male gender predominance. Majority were having at least one comorbidity. Type I perforations were found to me more in majority compared to other types. 12 among these cases required ICU admission, rest were managed in postoperative wards.

\section{CONCLUSION}

While dealing with an acute abdomen, we must keep in mind this unusual presentation of gallbladder perforation for timely intervention and management which is of crucial importance or else it may turn out to be fatal. It may be preoperatively diagnosed by imaging but most of the cases are with no particular radiological diagnosis and will be an unexpected finding intraoperatively.

\section{KEYWORDS}

Gallbladder Perforation, Acute Abdomen, Rare Presentation.

HOW TO CITE THIS ARTICLE: Gajendiraraj, Ramesh A, Balakrishnan R. Gallbladder perforation- Presenting as an acute abdomen. J. Evolution Med. Dent. Sci. 2017;6(80):5647-5651, DOI: 10.14260/Jemds/2017/1224

\section{BACKGROUND}

Gallbladder perforation is a rare but life-threatening complication of acute cholecystitis. ${ }^{1,2}$ About $2 \%$ to $15 \%$ of patients with acute cholecystitis ${ }^{3}$ associated with presence of gallbladder stone may be complicated with perforation of gallbladder. Most of the cases of GBP can only be diagnosed intraoperatively ${ }^{4,5}$ and so this continues to be an important problem for surgeons. ${ }^{6}$

Niemeir $^{7}$ classified gallbladder perforation as acute, subacute and chronic. Type I - free perforation and generalised biliary peritonitis, Type II - pericholecystic abscess and localised peritonitis, Type III - cholecystoenteric fistula. Each of these has different presentations. The patients with Type I mostly have risk factors leading to immunodeficiency that prevents localisation of the inflammation, thus leading to free perforation and generalised peritonitis. Type II present with features not

Financial or Other, Competing Interest: None.

Submission 21-06-2017, Peer Review 13-09-2017,

Acceptance 19-09-2017, Published 05-10-2017.

Corresponding Author:

Dr. A. Ramesh,

House No. 2, Block I,

Doctors Quarters, Adukkamparai, Vellore.

E-mail:ramesharunachalam81@gmail.com DOI: $10.14260 /$ jemds $/ 2017 / 1224$ typical of acute cholecystitis and Type III present with features similar to those of chronic cholecystitis, therefore it is difficult to identify unless there are some obstructive symptoms.

Advance age, male sex, associated diseases, fever $>38^{\circ}$ Celsius and marked leucocytosis will give signs of impending complication.

Acute abdomen refers to an acute intra-abdominal condition of abrupt onset, usually associated with severe pain due to inflammation, perforation, obstruction, infarction or rupture of abdominal organs and usually requiring emergency surgical intervention.

\section{Objective of the Study}

To estimate the proportion of gallbladder perforation in acute abdomen cases operated during the period of 2013 to 2016 A descriptive study.

\section{MATERIALS AND METHODS}

Study Design- Descriptive study.

Study Population- All patients presented with acute abdomen for a period of three years.

Inclusion Criteria- Presenting to casualty with acute abdomen.

- All age groups. 
Exclusion Criteria

- Trauma

- Malignancy

Study Period- From January 2013 to January 2016. Sample Size- 212 patients.

\section{Methodology}

Patients who received urgent surgical treatment for acute abdomen were reviewed. The diagnosis of GBP was based on intraoperative findings. The patients with acute cholecystitis, who received medical treatment and were operated on an elective basis, were excluded from this study. Perforations due to trauma, iatrogenic causes and gallbladder carcinoma were not included in this study.

The diagnosis of acute cholecystitis was made by the presence of findings (Right upper quadrant tenderness, guarding, positive Murphy sign, localised rebound, rigidity), leukocytosis, fever and USG findings like thickened gallbladder wall and/or pericholecystic fluid. If the abovementioned symptoms were present at the time of admission and the general physical condition of the patients allowed the procedure, immediate surgery was performed within the first 72 hours after administration of intravenous crystalloid solutions, analgesics and antibiotic (thirdgeneration cephalosporins) treatment. The patients having comorbidities like diabetes or cardiac and pulmonary disease after giving specific medical treatment underwent surgery.

The demographic data of patients, time gap from the onset of the symptoms to the time of surgery, associated comorbidities (like cardiovascular disease, diabetes mellitus, chronic obstructive pulmonary disease, immunosuppressive diseases or immunosuppressive treatment), American Society of Anesthesiologists (ASA) classification, laboratory data (blood investigations), imaging (like USG abdomen, CECT abdomen and x-ray abdomen), surgical procedures, postoperative complications, and postoperative duration of stay of the patients in ward were analysed.

The data were entered and analysed in SPSS version 16.

The percentage and proportions were calculated.

\section{Statistical Analysis}

All consecutive cases of gallbladder perforation were reviewed at Government Vellore Medical College Hospital from January 2013 to January 2016 from an electronic database and manually scrutinised the case notes of the patients in SPSS version 16. The proportion and percentage were calculated.

The parameters such as the demographics of the patient, the presenting symptoms of acute abdomen, comorbidities, investigations, treatment modalities were noted.

\begin{tabular}{|c|c|c|c|}
\hline Sl. No. & Gender & Total Operated & Percentage \\
\hline 1 & Male & 80 & 38.0 \\
\hline 2 & Female & 132 & 62.0 \\
\hline \multicolumn{3}{|c|}{$\begin{array}{c}\text { Table 1. Showing Gender Distribution } \\
\text { of Total Study Participants (n= 212) }\end{array}$} \\
\hline
\end{tabular}

\begin{tabular}{|c|c|c|}
\hline Clinical Diagnosis & Frequency & Percent \\
\hline Acute Cholecystitis & 58 & 27.0 \\
\hline Perforated Duodenal Ulcer & 42 & 20.0 \\
\hline Pneumonia & 21 & 10.0 \\
\hline Gastric Outlet Obstruction & 38 & 18.0 \\
\hline Small Bowel Obstruction & 30 & 14.0 \\
\hline Cholangitis & 23 & 11.0 \\
\hline Total & 212 & 100.0 \\
\hline \multicolumn{3}{|c|}{$\begin{array}{l}\text { Table 2. Showing Distribution of Study } \\
\text { articipants Based on the Clinical Diagnosis }\end{array}$} \\
\hline
\end{tabular}

AC - Acute Cholecystitis, PDU - Perforated Duodenal Ulcer, GOO- Gastric Outlet Obstruction, SBO- Small Bowel Obstruction.

Table 3. Showing the proportion of GBP among the total number of cases

\begin{tabular}{|c|c|c|}
\hline Total operated & GBP cases & Percentage \\
\hline 212 & 20 & 9.0 \\
\hline
\end{tabular}

GBP- Gallbladder perforation

\begin{tabular}{|c|c|c|}
\hline Gender & Frequency & Percentage \\
\hline Male & 12 & 60.0 \\
\hline Female & 8 & 40.0 \\
\hline Total & $\mathbf{2 0}$ & $\mathbf{1 0 0 . 0}$ \\
\hline \multicolumn{2}{|r|}{ Table 4. Showing Gender Distribution } \\
of GBP among Total Operated Cases
\end{tabular}

\begin{tabular}{|c|c|c|c|}
\hline Age & Total Operated & GBP & Percentage \\
\hline$<30$ & 96 & 6 & 16.0 \\
\hline $30-60$ & 84 & 6 & 14.0 \\
\hline$>60$ & 32 & 8 & 25.0 \\
\hline \multicolumn{3}{|c|}{ Table 5. Showing Frequency of GBP } \\
among Total Operated Cases in Age wise Distribution \\
\hline
\end{tabular}

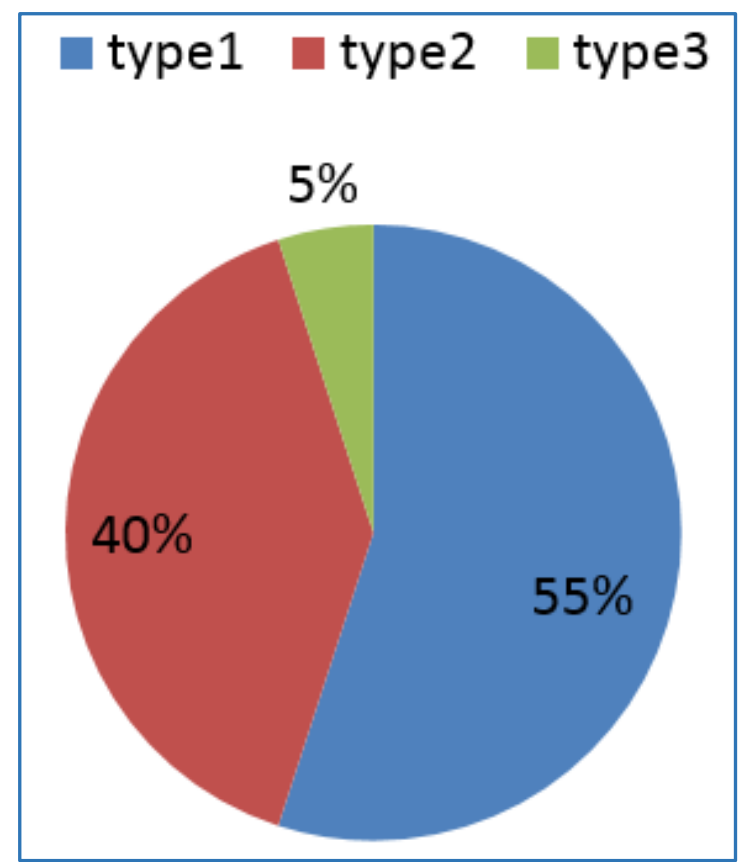

Figure 1. Showing Distribution of Patients with GBP based on the type of GBP 


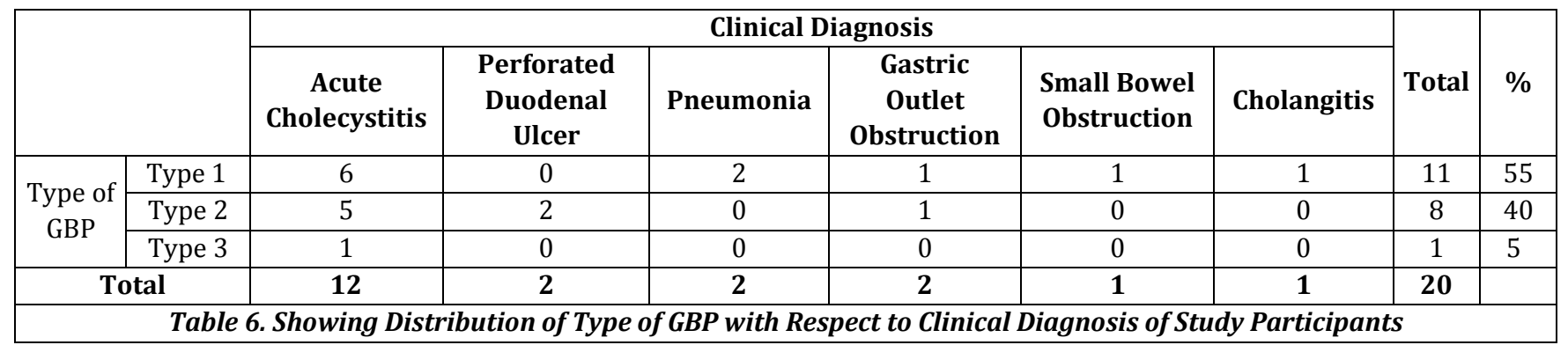

\begin{tabular}{|c|c|c|c|c|c|}
\hline \multicolumn{2}{|c|}{} & \multicolumn{2}{c|}{ Gender } & \multicolumn{2}{c|}{ Percentage } \\
\cline { 3 - 6 } \multicolumn{2}{|c|}{} & Male & Female & Male & Female \\
\hline \multirow{2}{*}{$\begin{array}{c}\text { Type of } \\
\text { GBP }\end{array}$} & Type 1 & 6 & 5 & 50.0 & 62.0 \\
\cline { 2 - 6 } & Type 2 & 5 & 3 & 41.0 & 38.0 \\
\cline { 2 - 6 } & Type 3 & 1 & 0 & 8.0 & 0 \\
\hline \multicolumn{2}{|c|}{ Total } & $\mathbf{1 2}$ & $\mathbf{8}$ & & \\
\hline \multicolumn{2}{|c|}{ Table 7. Showing Gender Distribution of Types of GBP } \\
\hline
\end{tabular}

\begin{tabular}{|c|c|c|}
\hline Comorbidities & Frequency & Percentage \\
\hline None & 3 & 15.0 \\
\hline HTN & 4 & 20.0 \\
\hline DM & 4 & 20.0 \\
\hline Dementia & 1 & 5.0 \\
\hline CVA & 1 & 5.0 \\
\hline HTN and CKD & 2 & 10.0 \\
\hline HTN and DM & 1 & 5.0 \\
\hline CKD and DM & 2 & 10.0 \\
\hline HTN, CKD and DM & 1 & 5.0 \\
\hline HTN, DM and CVA & 1 & 5.0 \\
\hline Total & 20 & 100.0 \\
\hline \multicolumn{3}{|c|}{$\begin{array}{c}\text { Table 8. Showing Proportion of Comorbidities } \\
\text { Among the Study Participants } \\
\end{array}$} \\
\hline
\end{tabular}

HTN- Hypertension, DM- Diabetes mellitus, CVACardiovascular accident, CKD- Chronic kidney disease

\section{RESULTS}

\section{Within the period of study we conducted-}

Among 212 cases, 80 male cases were operated and 132 female cases were operated for acute abdomen.

Among the 212 cases which were operated, about 20 patients were found to have Gallbladder perforation.

The male: female ratio of GBP was found to be 12:8.

Among less than 30 years group, 96 total operated cases were there, out of which 6 had GBP. Between 30 to 60 years group, 84 cases were operated out of which 6 had GBP. In 60 years above age group, 8 out of 32 operated cases had GBP.

The mean age at presentation was $51.65 \% \pm 20.1$ (range 27 - 84) years of the 20 GBP cases.

Majority having one comorbidity $(10 / 20,50 \%)$ and rest having three $(2 / 2010 \%)$, two $(5 / 2025 \%)$ zero $(3 / 2015 \%)$. 11 were found to have type I perforation (11/20 55\%), 8 were found to have type II (8/20 40\%) and 1 with type III $(1 / 205 \%)$. We found that the disease occurs more frequently in elderly patients, and the cases with type III perforation were older than those in the type I and II groups, which is in accordance with other reports. Among the 20 GBP cases, 12 cases needed ICU admissions, rest of the cases had care in post-operative ward. As per our case series, prevalence of gallbladder perforation among the study participants was found to be about $9 \%$.

\section{DISCUSSION}

Gallbladder perforation (GBP) is a rare and life-threatening complication of acute cholecystitis. ${ }^{1,2}$ It is not possible to predict reliably in which patients this complication will develop. ${ }^{8}$

Acute uncomplicated cholecystitis is more common among females, with a female to male ratio of two to one: However, GBP is more frequent in the male gender.1,9,10

Study reported that there were a greater number of men than women with type I and type II perforations, as compared to those with type III perforations.9,10,11,8 In our study, patients with type I and type II perforations tended to have a higher incidence of male gender compared to patients with type III perforations, but these differences failed to achieve statistical significance.

Gallbladder is a pear-shaped reservoir about 5 to $12 \mathrm{~cm}$ located inferior to liver in gallbladder fossa. GB has fundus, body, infundibulum and neck. Fundus is the dilated part of gallbladder which is adherent to the under surface of liver. Neck of the gallbladder has a narrow angulated distal portion called Hartmann's pouch which is located in the infundibular region. It is the common site where stones occur.

Gallbladder drains into the common bile duct through cystic duct. Cystic duct is $3 \mathrm{~cm}$ long and is lined by cuboidal epithelium. Due to the presence of prominent circular muscle fibres underneath, the cystic duct has many mucosal folds. Lumen of cystic duct is usually 1 to $3 \mathrm{~mm}$ in diameter. Common bile duct is formed by joining of cystic and common hepatic duct. Common hepatic duct is formed by the union of right and left hepatic ducts. It is about $3 \mathrm{~cm}$ long. Common bile duct is about $8 \mathrm{~cm}$ long. It has four parts- supraduodenal, retroduodenal, infraduodenal and intraduodenal parts. Along with the pancreatic duct, the common bile duct forms ampulla of Vater controlled by sphincter of Oddi which ends by an opening into the second part of duodenum. Contraction of gallbladder produces a functional valve motion. The valve is called as valve of Heister. The wall of cystic duct is surrounded by a sphincter structure called sphincter of Lutkens. A spiral fold keeps the cystic duct open for bile drainage.

Gallbladder gets its blood supply from right hepatic artery through cystic artery. Cystic artery is an end artery. There is also a cystic vein which drains directly into the portal vein from the neck of gallbladder and this accounts for the spread of malignancy of gallbladder to the liver.

Calot's triangle is also known as cholecystohepatic triangle bounded above by inferior surface of right lobe of liver, laterally by the cystic duct, gallbladder and medially by the common hepatic duct. Calot's triangle is an important landmark for identifying the cystic duct and cystic artery during cholecystectomy so that damage to extrahepatic biliary tree can be avoided. The contents of Calot's triangle 
are lymph node of Lund and cystic artery which is a branch of right hepatic artery.

Gallbladder acts as a reservoir for bile. Bile which is excreted by liver is stored in gallbladder, about 500 to 1000 $\mathrm{mL}$ per day. Food contents in the duodenum will stimulate the release of cholecystokinin and causes contraction of gallbladder. Gallbladder helps in concentrating bile. Bile is $98 \%$ water and due to absorption of water, sodium chloride and bicarbonate, bile gets concentrated about 5 to 10 times. Gallbladder secretes about $20 \mathrm{~mL} /$ mucus per day. Obstruction of cystic duct thus produces mucocoele of gallbladder.

Acute cholecystitis usually occurs by impaction of gallstone in Hartmann's pouch obstructing the cystic duct. Causative agents involved are E. coli, Klebsiella, Pseudomonas, Proteus, Streptococcus faecalis, Salmonella and Clostridium welchii. Acute cholecystitis is classified as calculus and acalculous cholecystitis. Mode of infection is mainly through haematogenous spread and bile.

Obstruction in Hartmann's pouch by gallstones causes bile stasis, wall oedema, bacterial infection and results in acute cholecystitis and its effects. GB will be distended, areas of necrosis and patchy gangrene may occur in severe cases. Complications of acute cholecystitis include perforation, peritonitis, pericholecystic abscess, empyema of GB, cholangitis, septicaemia and gangrenous GB. Clinically there will be sudden onset of pain in right hypochondrium, fever with tenderness, guarding and rigidity, and palpable tender gallbladder.

Clinical signs in acute cholecystitis are Murphy's sign which is because of the inflamed gallbladder coming in contact with the abdominal wall under the palpating fingers and producing pain which is diagnostic of acute cholecystitis. Boa's sign is an area of hyperaesthesia between $9^{\text {th }}$ and $11^{\text {th }}$ ribs posteriorly on the right side. Upper abdominal guarding, rigidity may be present. Vague mass consisting of inflamed gallbladder, omentum, inflammatory exudates can also be felt sometimes. Hence, even if a perforation occurs the chance of generalised peritonitis is uncommon.

Cholecystectomy is the surgical removal of gallbladder. It can be done through open or laparoscopically. Indications are symptomatic gallstones, acute and chronic cholecystitis, acalculous cholecystitis, empyema of GB, mucocoele of GB. Prophylactic cholecystectomy is done in diabetic patients, congenital haemolytic anaemia and patients who underwent bariatric surgery. There are two approaches by which cholecystectomy can be done - Open and laparoscopic method.

In case of open cholecystectomy, the incisions followed are -right subcostal (Kocher's), right paramedian incision, horizontal incision, Mayo-Robson incision. After opening the abdomen, colon is pushed downwards and stomach is pushed medially. Duct first method and fundus first method of approaching gallbladder are used. In duct first method, Calot's triangle is dissected. Cystic artery is identified and ligated. Cystic duct is ligated close to the gallbladder. Gallbladder is separated from gallbladder fossa and removed. Fundus first method is done in case of difficult gallbladder due to dense adhesions. Fundus is separated from the liver bed. Dissection is carried proximally until the cystic duct and cystic artery is identified and they are then ligated.
Laparoscopic cholecystectomy is the most popular method to remove gallbladder. It is the gold standard treatment for gallbladder. Ports are $10 \mathrm{~mm}$ port in umbilicus to pass $10 \mathrm{~mm}$ telescope, $10 \mathrm{~mm}$ port in midline epigastrium as working channel and two $5 \mathrm{~mm}$ ports at midclavicular and anterior axillary line in subcostal region. After creating pneumoperitoneum with 12 to $14 \mathrm{~mm}$ pressure, $10 \mathrm{~mm}$ umbilical port is inserted. Telescope is passed. Under vision remaining ports are inserted. Using lateral $5 \mathrm{~mm}$ port, gallbladder grasper forceps is passed and fundus of gallbladder is held and pushed up towards the diaphragm. With middle $5 \mathrm{~mm}$ port, grasper is passed to hold Hartmann's pouch. With $10 \mathrm{~mm}$ port, dissector is passed using reducer. Calot's triangle is dissected. Cystic duct is identified. Adhesions are released. First posterior dissection is completed. Cystic artery is above and deep to cystic duct. Cystic duct is clipped. Cystic artery is also clipped. Gallbladder is dissected off the liver bed using cautery. Gallbladder is removed through $10 \mathrm{~mm}$ working port with reducer. A tube drain kept through lateral port. The complications which can occur in cholecystectomy are infection and subphrenic abscess, bleeding from cystic artery, liver bed, injury to CBD or hepatic duct, bile leak, biliary fistula, biliary stricture, injuries to colon, duodenum, mesentery.

Type I perforation differs from Type II in clinical diagnosis (e.g. peritonitis) and radiological support and treatment proceeded straight away with laparotomy followed by cholecystectomy or cholecystotomy. ${ }^{12}$ Type II perforation is more complex compared to Type I. Type II associated with more comorbidities. ${ }^{1}$ Multimodality approach and identifying accurately the type of perforation will help in moving on to effective management of the case. $13,14,15,16$

\section{CONCLUSION}

While dealing with an acute abdomen, we must keep in mind this unusual presentation of gallbladder perforation for timely intervention and management which is of crucial importance or else it may turn out to be fatal. It may be preoperatively diagnosed by imaging but most of the cases are with no particular radiological diagnosis and will be an unexpected finding intraoperatively.

\section{REFERENCES}

[1] Derici H, Kara C, Bozdag AD, et al. Diagnosis and treatment of gallbladder perforation. World J Gastroenterol 2006;12(48):7832-6.

[2] Bedirli A, Sakrak O, Sozuer EM, et al. Factors effecting the complications in the natural history of acute cholecystitis. Hepatogastroenterology 2001;48(41):1275-8.

[3] Stefanidis D, Sirinek KR, Bingener J. Gallbladder perforation: risk factors and outcome. J Surg Res 2006;131(2):204-8.

[4] Roslyn JJ, Thompson JE, Darvin H, et al. Risk factors for gallbladder perforation. Am J Gastroenterol 1987;82(7):636-40.

[5] Ong CL, Wong TH, Rauff A. Acute gall bladder perforation-a dilemma in early diagnosis. Gut 1991;32(8):956-8. 


\section{Jemds.com}

[6] Alvi AR, Ajmal S, Saleem T. Acute free perforation of gall bladder encountered at initial presentation in a 51 years old man: a case report. Cases J 2009;2:166.

[7] Niemeier OW. Acute free perforation of the gall bladder. Ann Surg 1934;99(6):922-4.

[8] Tanaka M, Takahashi H, Yajima Y, et al. Idiopathic perforation of the gallbladder: report of a case and a review of the Japanese literature. Surg Today 1997;27(4):360-3.

[9] Lein HH, Huang CS. Male gender: risk factor for severe symptomatic cholelithiasis. World J Surg 2002;26(5): 598-601.

[10] Abu-Dalu J, Urca I. Acute cholecystitis with perforation into the peritoneal cavity. Arch Surg 1971;102(2): 108-10.

[11] Doherty GM, Way LW. Biliary tract. In: Way LW, Doherty GM. (eds). Current surgical diagnosis \& treatment. $11^{\text {th }}$ edn. New York: McGraw-Hill, 2003:595-624.

\section{Original Research Article}

[12] Lennon F, Green WE. Perforation of the gallbladder. A review of 32 cases. J R Coll Surg Edinb 1983;28(3): 169-73.

[13] Menakuru SR, Kaman L, Behera A, et al. Current management of gall bladder perforations. ANZ J Surg 2004;74(10):843-6.

[14] Sood B, Jain M, Khandelwal N, et al. MRI of perforated gall bladder. Australas Radiol 2002;46(4):438-40.

[15] Kim PN, Lee KS, Kim IY, et al. Gallbladder perforation: comparison of US findings with CT. Abdom Imaging 1994;19(3):239-42.

[16] Forsberg L, Andersson R, Hederstrom E, et al. Ultrasonography and gallbladder perforation in acute cholecystitis. Acta Radiol 1988;29(2):203-5. 